\title{
Poverty of stimulus and absence of cause: Some questions for Felin and Foss
}

\author{
Geoffrey M. Hodgson and Thorbjørn Knudsen
}

3 January 2011

For Journal of Institutional Economics

\begin{abstract}
The Business School, University of Hertfordshire, De Havilland Campus, Hatfield, Hertfordshire AL10 9AB, UK and

Department of Marketing \& Management, University of Southern Denmark, Odense Campus, DK-5230, Odense M,

Denmark
\end{abstract}

KEY WORDS: routines, habits, causality, evolution, uncaused cause.

JEL classification

\begin{abstract}
We examine an aspect of the argument of Teppo Felin and Nicolai Foss (2011) where they reject the claim of Hodgson and Knudsen (2004) that habits depend crucially on stimuli from the social environment. We argue that while rightly stressing human agency they also create a false dichotomy between agential and environmental factors in the explanation. Felin and Foss create further confusion by hinting - without adequate clarification - at an untenable notion of human agency as an uncaused cause. We raise several questions of clarification for these authors.
\end{abstract}




\title{
Poverty of stimulus and absence of cause: Some questions for Felin and Foss
}

\author{
Geoffrey M. Hodgson and Thorbjørn Knudsen
}

We welcome the stimulating contribution by Teppo Felin and Nicolai Foss (2011) to the analytical literature on routines. In this note we wish to briefly respond to one of their arguments and raise some questions for them concerning somewhat cryptic aspects of their stance.

We understand that Felin and Foss wish to emphasise the role of human agency and individual psychology in the analysis of routines. In general terms we applaud that stance. But, as elaborated elsewhere, we think that the term 'methodological individualism' is misleading to describe such a view (Hodgson 2007). Any viable approach to the analysis of institutions in particular and social phenomena in general must incorporate both individuals and structured relations between individuals; the label of methodological individualism biases the account in one direction only. Posing individuals versus social structure as alternative explanantia is a false dichotomy.

Felin and Foss quote our view on habits - which we regard as basic individual blocks for institutions and routines - where they 'depend crucially upon stimuli from the social environment' (Hodgson and Knudsen 2004, p. 289). Felin and Foss (2011) respond to the quoted passage: 'Our point, on the other hand, is that stimuli and the environment necessarily cannot - given the poverty and degeneracy of the stimuli - be ascribed as the causal factors of behavior and capability.'

This is yet another case of ambiguity and false dichotomy. Note the phrase 'on the other hand' depicts a dichotomy where none exists. Our position that habits 'depend crucially upon stimuli from the social environment' is perfectly consistent with Felin and Foss's argument that they are insufficient as causes of capabilities or behaviour. We fully accept that they are insufficient: individual capabilities and behaviour also depend on individual personality, idiosyncrasy and (in part) on genetic make-up. The 'stimuli from the social environment' are necessary but insufficient.

Our model of habit formation that Felin and Foss (2011) take issue with captures the accumulation of experience as an instance of sequential interaction between environmental variables and internal states of agents. This modelling strategy is quite common in behavioural and evolutionary approaches (March and Simon 1958, Nelson and Winter 1982). The agents' propensity to acquire and interpret environmental feedback depends on their internal state, but their internal state adapts in response to the feedback they seek from the environment (including actions of other agents). As in other models of statistical learning, repetition of a particular action improves assessment of the mapping between action and 
consequence. ${ }^{1}$ In contrast, Felin and Foss (2011) portray the agents' experiences as instances of environmental stimuli. Their characterization of experience is rather strange because it ignores the mapping between environmental variables and internal states, a main feature of our model that is widely used in the behavioural and evolutionary literature (e.g. March and Simon 1958, Nelson and Winter 1982). Felin and Foss (2011) thereby assert the importance of human agency by misrepresenting the common characterization of causal arguments in this line of work. ${ }^{2}$

But asserting the importance of human agency does not give an excuse to terminate the search for causal explanation, which is the essence of science. We maintain that we are also required to explain the causes behind individual capacities and intentions, and not regard these as somehow uncaused, or beyond the reach of science

In this area, the ambiguities in the position of Felin and Foss (2011) become further apparent when they argue for 'free will' and some causal 'wiggle room' or 'Spielraum'. They use the term 'indeterminacy' - again without adequate definition. Given these allusions, do they regard intentions as (partially) uncaused, thus beyond the reach of (any eventual) causal explanation? For them, are (some portion of) intentions entirely caused or not?

Clearly we are getting into very deep philosophical water here. But it is reasonable to ask for some clarifications regarding their position.

We take a view that is consistent with what we believe to be the majority position among modern philosophers. We uphold that every phenomenon is caused and that the primary goal of science is causal explanation (e.g. Bunge 1959). We also take a position known as compatibilism, which upholds that a notion of free will is compatible with the proposition that wills are themselves caused (e.g. Frankfurt 1999). A view that human agency is somehow uncaused would create a no-go area for science and create an untenable dualism or mysticism. It would be inconsistent with the fact of human evolution from earlier species and ultimately from inorganic matter. We also note that terms such as determinism and indeterminacy are highly ambiguous and are used in several different and conflicting ways (Bunge 1959, Hodgson 2004). Again we would be interested in the more precise views of Felin and Foss.

Having made our own marks in the sand - albeit sketchily - it is reasonable to ask for clarification on all the above points. Does the 'poverty of stimulus' argument imply that internal states are ultimate causes of human behaviour? Is the 'poverty of stimulus' argument intended to lead to a notion of human agency as an uncaused cause? For our part, we fully accept that each individual is unique and that variation between individuals renders inadequate any causal explanation based on stimulus or context alone. Indeed that stance is essential to the Darwinian approach that we have developed elsewhere (Hodgson and Knudsen 2010).

Felin and Foss present some positions as being in opposition, when they are logically compatible. They are frequently unclear in their use of terminology, and they confuse claims of partial and complete determination. Further debate will be enhanced by some clear answers.

\footnotetext{
1 From standard models of statistical learning, it is easy to see why repetition can be useful. When the propagation of feedback is masked by noise, a decision maker can improve expectations about possible consequences of an action if she increases the sample size of that action (Gittins 1989, March 1991). 2 For example, Felin and Foss (2011) ignore March and Simon's (1958) careful discussion of internal states of
human actors (including memory conditions).
} 


\section{References}

Bunge, Mario A. (1959) Causality: The Place of the Causal Principle in Modern Science (Cambridge, MA: Harvard University Press).

Felin, Teppo and Foss, Nicolai (2011) 'The endogenous origins of experience, routines, and organizational capabilities: the poverty of stimulus', Journal of Institutional Economics, 7(2), June. DOI: 10.1017/S1744137410000214.

Frankfurt, Harry (1999) Necessity, Volition, and Love (Cambridge: Cambridge University Press).

Gittins, John C. 1989. Multi-armed Bandit Allocation Indices (New York: John Wiley and Sons).

Hodgson, Geoffrey M. (2004) 'Darwinism, Causality and the Social Sciences', Journal of Economic Methodology, 11(2), June, pp. 175-94.

Hodgson, Geoffrey M. (2007) 'Meanings of Methodological Individualism', Journal of Economic Methodology 14(2), June, pp. 211-26.

Hodgson, Geoffrey M. and Knudsen, Thorbjørn (2004) 'The Firm as an Interactor: Firms as Vehicles for Habits and Routines', Journal of Evolutionary Economics, 14(3), July, pp. 281-307.

Hodgson, Geoffrey M. and Knudsen, Thorbjørn (2010) Darwin's Conjecture: The Search for General Principles of Social and Economic Evolution (Chicago: University of Chicago Press).

March, James G. (1991) 'Exploration and exploitation in organizational learning'. Organization Science, 2(1), pp. 71-87.

March, James G. and Simon, Herbert A. (1958) Organizations (New York: John Wiley).

Nelson, Richard R. and Winter, Sidney G. (1982) An Evolutionary Theory of Economic Change (Cambridge, MA: Harvard University Press). 